\title{
Effects of acidic water in combination with aluminum on swimming behavior and survival of yolk-sac larval in Goldfish (Carassius auratus gibelio)
}

\author{
Vahid Taghizadeh*, Mohammad Reza Imanpoor, Mahboubeh Hosseinzadeh and Hajar Azarin
}

\begin{abstract}
Yolk-sac fry of Goldfish (Carassius auratus gibelio) were exposed to various concentrations of Al and pH for 3,7 and 10 days. In this study number of dead fish, total length of larvae, yolk sac length, swimming activity, the number of gill cover movements and the number of heart beat was measured. The lowest and highest number of gill cover movements belong to the waters containing $50 \mathrm{mg} \mathrm{L-1}$ of aluminum, pH 5.25 and acidic waters with pH 6.7 respectively. There was no significant difference in the number of heartbeat between control group and larvae exposure to acidic waters with pH 6.7 and waters containing $150 \mathrm{mgL}-1$ of aluminum and the highest number of heartbeat belong to these larvae than other experiment doses. The larval of Goldfish in the all experiment doses lost their swimming ability after 3 days. The highest number of swimming larvae and also lowest number of nonswimming larvae significantly belong to control group compared to other experiment doses $(p<0.05)$. The larval in the control group only were maintained their swimming activity after 7 and 10 days and in the all experiment treatments lost their swimming ability. There was significant difference in the number of dead larvae and the number of non-swimming larvae between control group and larvae exposure to acidic waters and waters containing 300 mgL-1 of aluminum and pH $4.75(p<0.05)$ and lowest number of non-swimming larvae was observed in the control group. Also the highest of yolk sac length belong to the waters containing $600 \mathrm{mgL}-1$ of aluminum and pH 4.75. The larvae of Goldfish were not survived in the waters containing 300 and 600 mgL-1 of aluminum and waters with low acidity after 7 days.
\end{abstract}

Keywords: Carassius auratus gibelio, acidic waters, aluminum, swimming activity, heartbeat

\section{Introduction}

Fish mortality in acidic waters is determined by multiple factors, including $\mathrm{pH}$, inorganic monomeric (exchangeable) $\mathrm{Al}$ and $\mathrm{Ca}^{+2}$ among the most important. Aluminum is a common element in the Earth crust. The solubility of aluminum in water increases as $\mathrm{pH}$ decreases (Smith and Haines, 1995).

The toxic effect of aluminum on fish varies with both fish species and life stages. Yolk-sac fry are more sensitive than eggs, but following yolk-sac absorption, sensitivity increases yet further. It is generally believed that

\footnotetext{
* Correspondence: Vahid_taghizadeh54@yahoo.com

Department of Fisheries, Gorgan University of Agricultural Sciences and Natural Resources, Gorgan, Iran
}

sensitivity to aluminum toxicity at low $\mathrm{pH}$ increases with age (Catla 2002). The threshold $\mathrm{pH}$ values with respect to survival and swimming activity (lowest $\mathrm{pH}$ for survival and safe $\mathrm{pH}$ ) were, dependingon the $\mathrm{Al}$ concentration.

Fish reproduction is considered sensitive to water acidification (Peterson et al., 1982), as reflected in fish population decline in lakes where, overall, few adult fish mortalities have been reported (Rask and Tuunainen, 1990).

In yolk-sac fry, the routine metabolic rate may, in contrast, be reduced as acidity decreases their swimming activity as documented mainly in salmonoid fishes (Sayer et al., 1993a), but also in such species as small Mouth bass (Micropterus dolomieu) (Kane and 
Rabeni, 1987), Whitefish, Pike-perch, Roach and Pike (Vuorinen et al. 1993).

Aluminum is one of the important factors in the toxicity of acidified waters to freshwater fish species because low $\mathrm{pH}$ and high concentrations of $\mathrm{Al}$ have been of particular concern in affected waters. Al toxicity is mostly associated with the acidification because its solubility increases exactly below $\mathrm{pH} 4.0$ and it becomes the most important factor responsible for fish kills in acidified water bodies (Mani Sharma, 2003).

Acidic water and $\mathrm{Al}$ interferes with the ionbalance of fish by increasing ion efflux and by inhibiting the uptake of essential ions from the environment. Acidic water and $\mathrm{Al}$ also $\mathrm{Ca}$ use internal hypoxia which is seen, for example, as increased ventilation rate and may result from the precipitation or polymerization of $\mathrm{Al}$ onto the gills. Increased mucus secretion, and thickening or more striking changes in the bronchial epithelium may also occur. Innewly-hatched fry the gas exchange is mainly cutaneous and the skin evidently functions in ion-exchange also. Aluminum in acidic water clearly augments both the decrease of activity and retardation of yolk absorption and consequently the development and growth of yolk-sac fry, seen especially in species with a large yolk-sac and a long yolk-sac phase (Keinanen et al., 2000).

Sub lethal acidified conditions may increase the basal metabolic rate because more energy is needed to maintain the ion balance (McCormick et al. 1989; Leino et al., 1990; Wilson et al., 1994). Research into the susceptibility of early life phases of fish to acidity has mainly focused on salmonoid species (Sayer et al. 1993b).

However, little is known concerning the basis for the species differences in tolerant of acidified waters and aluminum. To accomplish this, we exposed yolk-sac fry of Goldfish to realistic conditions of acidity alone, and in combination with aluminum. Thus, the main goal of the present study was to find the physiological basis for the differences in sensitivity to acidic water and $\mathrm{Al}$ in newlyhatched yolk-sac fry of Goldfish. This was investigated by exposing newly-hatched yolk-sac fry to various combinations of $\mathrm{pH}$ values and $\mathrm{Al}$ concentrations, and measuring parameters such as yolk-sac length, swimming activity, the number of gill cover movements and the number of heartbeat in yolk-sac fry of Goldfish (Carassius auratus gibelio).

\section{Materials and methods}

Three experiments were performed in which newly-hatched yolk-sac fry were exposed to different combinations of acidic water and $\mathrm{Al}$ in the first experiment (experiment 1) mortality, swimming activity, movements of the operculum, and in second experiment (experiment 2) mortality, swimming activity and yolk-sac length and in third experiment (experiment 3) mortality, swimming activity, total length, yolk-sac length, heartbeats and movements of the operculum were measured.

\section{Fish experiment}

In this study we used from Goldfish larvae. Two injections of Ova prim were used to simulate final maturation and artificial propagation in the female Goldfish broodstock. In females the first injection (5\% of total dose) was made at $10 \mathrm{pm}$ and second (95\% of total dose) $24 \mathrm{~h}$ later at 8 am hours. And males were injected as time as the second injection in females. And 24-48 h after final injection Oocytes and milt were stripped and mixed together using a light feather. After adhesion removal (2 ppt $\mathrm{NaCl}$ solution), the fertilized eggs were transferred into glass aquarium supplied with gentle aeration. After $48 \mathrm{~h}$ the eggs were hatched (at $23^{\circ} \mathrm{C}$ ). Newly-hatched larvae with $7 \pm 1 \mathrm{~mm}$ length and $32.33 \pm$ $1.15 \mathrm{~mm}$ yolk-sac length were used in the tests.

\section{Preparation of test solution}

The test waters for experiments were prepared from urban water, after chlorinization, which also served as the control. The test water for experiments 1,2 and 3 were made by dissolving aluminum $\left(\mathrm{Al}_{2}\left(\mathrm{SO}_{4}\right)\right)_{3}$ into deionized water. The $\mathrm{pH}$ of test solutions was checked daily and fixed by adding Tris and Tris Hcl. The water was aerated after each acid addition. A series of test solutions was made for each experiment and was used throughout the test.

\section{Experimental protocol}

Exposures were conduct in glass jars, the water volume of which was $300 \mathrm{ml}$. each experiment was carried out as three replicates using 30 yolk-sac fry. Temperature was maintained at $18 \pm 2^{\circ} \mathrm{C}$. Approximately $80 \%$ of the test ware was renewed at least every second day. Fry were not fed; they resorbed their yolk during the experiments.

\section{Experiment 1}

Mortality, swimming activity, movements of the operculum were recorded. Goldfish fry were exposed for 3 days to acid water at pH 5.00,5.25, 5.75, and 6.7, and to $\mathrm{Al}$ in concentrations of $0,50,150$, and $250 \mathrm{mg} \mathrm{L}^{-1}$. The water temperature was $18 \pm 2^{\circ} \mathrm{C}$ (mean $\pm \mathrm{SD}$ of daily measurements). Dead fry were removed and numbers of swimming and non-swimming fry were registered daily. The movements of the operculum of fry were monitored under the microscope. Before the estimations, the fry were allowed to calm down for at least $30 \mathrm{~s}$ after putting them onto a Petri dish the time for 30 movements of the operculum was measured three times in ten fry in each group. 


\section{Experiment 2}

Mortality, swimming activity and yolk-sac length were recorded. Goldfish fry were exposed for 7 days to acid water at $\mathrm{pH} 4,4.25,4.75$ and 5 , and to $\mathrm{Al}$ in concentration of 0,300 and $600 \mathrm{mg} \mathrm{L}^{-1}$. The water temperature was $18 \pm 2^{\circ} \mathrm{C}$ (mean $\pm \mathrm{SD}$ of daily measurements).

\section{Experiment 3}

Mortality, swimming activity, total length, heartbeats and movements of the operculum were measured. Goldfish fry were exposed for 10 days to acid water at $\mathrm{pH} 6.50$, and to $\mathrm{Al}$ in concentrations of 0,50 , and $100 \mathrm{mg} \mathrm{L}^{-1}$. The water temperature was $18 \pm 2^{\circ} \mathrm{C}$ (mean $\pm \mathrm{SD}$ of daily measurements). The movements of the operculum of fry were monitored under the microscope. Before the estimations, the fry were allowed to calm down for at least $30 \mathrm{~s}$ after putting them onto a Petri dish the time for 30 movements of the operculum was measured three times in ten fry in each group. Similarly, eight fry from each group were used to measure the time needed for 30 heartbeats and at least three repetitive measurements were taken.

\section{Data analyze}

Two-way ANOVA was applied to test the effects of $\mathrm{Al}$ and $\mathrm{pH}$ on length, movements of operculum, heartbets, and summing activity. The differences between the means were tested by Duncan test at the $95 \%$ confidence level.

\section{Results}

After $42 \mathrm{~h}, 100 \%$ mortality was observed in pH 5. 25 at AL $0,150 \mathrm{mg} \mathrm{L}^{-1}$ and 250 , $\mathrm{pH} 5.75$ at $\mathrm{Al} 50$, and $150 \mathrm{mg} \mathrm{L}^{-1}$ in treatment 1 , and in $\mathrm{pH} 4$ at AL $0,300,600 \mathrm{mg} \mathrm{L}^{-1}$, $\mathrm{pH} 4.25$ at $\mathrm{Al} 300$ and $600 \mathrm{mg} \mathrm{L}^{-1}, \mathrm{pH} 4.5$ at $\mathrm{Al} 300$ and $600 \mathrm{mg} \mathrm{L}^{-1}$ and in $\mathrm{pH} 5$ at $\mathrm{Al} 300$ and $600 \mathrm{mg} \mathrm{L}^{-1}$ in treatment 2 .
The results of Analyze-Variance and the means comparison of evaluated parameters of yolk-sac fry of Goldfish after exposure to different concentrations of $\mathrm{Al}$ and $\mathrm{pH}$ for 3 days are shown in Table 1.

The larvae of Goldfish in the all experiment doses lost their swimming ability after 3 days and all larvae were non-swimming in acidic waters with $\mathrm{pH} 6.7$ and waters containing $50 \mathrm{mg} \mathrm{L}^{-1}$ aluminum and $\mathrm{pH} 5.25$ and $\mathrm{pH}$ 6.7, waters containing $50 \mathrm{mg} \mathrm{L}^{-1}$ of aluminum and $\mathrm{pH}$ 6.7 and also waters containing $250 \mathrm{mg} \mathrm{L}^{-1}$ aluminum and $\mathrm{pH} 6.7$ (Table 1). The highest number of nonswimming larvae was observed in the water containing $50 \mathrm{mg} \mathrm{L}^{-1}$ aluminum and $\mathrm{pH} 5.25$ and $\mathrm{pH} 6.7$ and also waters with $150 \mathrm{mg} \mathrm{L}^{-1}$ aluminum and $\mathrm{pH}$ 6.7. The highest number of live and swimming larvae and also lowest number of non-swimming larvae significantly belong to control group compared to other experiment doses $(\mathrm{P}<0.05)$. There was no significant difference in the number of gill cover movements between control group and larvae exposure to acidic waters with $\mathrm{pH} 5.57$ and $\mathrm{pH}$ 6.7, waters containing $50 \mathrm{mg} \mathrm{L}^{-1}$ of aluminum and $\mathrm{pH} 6.7$ and also waters containing $150 \mathrm{mg} \mathrm{L}^{-1}$ of aluminum and $\mathrm{pH} 6.7$ $(\mathrm{P}<0.05)$. Also, the highest number of gill cover movements was observed in these groups (Table 1).

Yolk-sac fry of Goldfish were exposed to concentrations of 0,300 and $600 \mathrm{mgL}^{-1}$ of aluminum and $\mathrm{pH} 4$, 4.25, 4.5, 4.75 and 5 for 10 days but after 7 days, only control group and larvae were exposed to acidic waters with $\mathrm{pH} 4.25,4.5,4.75$ and 5 and waters containing 300 $\mathrm{mg} \mathrm{L}^{-1}$ of aluminum and $\mathrm{pH} 4.57$ and containing 600 $\mathrm{mg} \mathrm{L}^{-1}$ of aluminum and $\mathrm{pH} 4.57$ remained alive. The results of the means comparison of larvae were placed at doses above are shown in Table 2.

As shown in Table 2, the larvae in the control group only were maintained their swimming activity after 7

Table 1 The means comparison of evaluated parameters of yolk-sac fry of Goldfish after exposure to different concentrations of $\mathrm{Al}\left(\mathrm{mg} \mathrm{L}^{-1}\right)$ and $\mathrm{pH}$ for 3 days

\begin{tabular}{|c|c|c|c|c|}
\hline Al- $\mathrm{pH}$ & Dead (Number) & $\begin{array}{l}\text { Gill cover movements } \\
\text { (Number) }\end{array}$ & $\begin{array}{l}\text { Non-swimming } \\
\text { (Number) }\end{array}$ & $\begin{array}{l}\text { Swimming } \\
\text { (Number) }\end{array}$ \\
\hline Control & ${ }^{d} 0 \pm 0$ & ${ }^{a} 1.52 \pm 19.33$ & ${ }^{d} 0 \pm 0$ & ${ }^{\mathrm{a}} 0 \pm 30$ \\
\hline $0-5.75$ & ${ }^{c} 9.60 \pm 8.66$ & ${ }^{a} 4.72 \pm 19.66$ & ${ }^{b} 9.6 \pm 21.33$ & ${ }^{c} 0 \pm 0$ \\
\hline $0-6.7$ & ${ }^{d} 0 \pm 0$ & ${ }^{a} 2 \pm 17$ & ${ }^{\mathrm{a}} 0 \pm 30$ & ${ }^{c} 0 \pm 0$ \\
\hline $50-0$ & ${ }^{d} 1.5 \pm 1.33$ & $\mathrm{~b}_{2} \pm 17$ & $\mathrm{a}_{1.52 \pm 28.66}$ & ${ }^{c} 0 \pm 0$ \\
\hline $50-5.25$ & ${ }^{d} 0 \pm 0$ & $\mathrm{~b}_{4.9} \pm 16.66$ & ${ }^{\mathrm{a}} 0 \pm 30$ & ${ }^{c} 0 \pm 0$ \\
\hline $50-6.7$ & ${ }^{d} 0 \pm 0$ & ${ }^{a} 2.51 \pm 19.33$ & ${ }^{\mathrm{a}} 0 \pm 30$ & ${ }^{c} 0 \pm 0$ \\
\hline $150-0$ & ${ }^{d} 0 \pm 0$ & ${ }^{a} 5.56 \pm 19$ & ${ }^{\mathrm{a}} 0 \pm 30$ & ${ }^{c} 0 \pm 0$ \\
\hline $150-5.75$ & $b_{2} \pm 24$ & $b_{2.6 \pm 16}$ & $c_{2} \pm 6$ & ${ }^{c} 0 \pm 0$ \\
\hline $150-6.7$ & ${ }^{d} 0 \pm 0$ & ${ }^{\mathrm{a}} 6.5 \pm 18.33$ & ${ }^{\mathrm{a}} 0 \pm 30$ & ${ }^{c} 0 \pm 0$ \\
\hline $250-5.75$ & $b_{5} \pm 20$ & ${ }^{a} 7.3 \pm 23.66$ & $c_{5} \pm 10$ & ${ }^{c} 0 \pm 0$ \\
\hline $250-6.7$ & ${ }^{d} 0 \pm 0$ & ${ }^{\mathrm{a}} 10.9 \pm 26.33$ & ${ }^{a} 1.7 \pm 29$ & $b_{1.7 \pm 1}$ \\
\hline
\end{tabular}

Different letters denote a significant difference at the same column $(P<0.05)$. 
Table 2 The means comparison of evaluated parameters of yolk-sac fry of Goldfish after exposure to different concentrations of $\mathrm{Al}$ and $\mathrm{pH}$ for 7 days

\begin{tabular}{|c|c|c|c|c|c|c|c|}
\hline Parameters & Control & $4.25-0$ & $4.5-0$ & $4.75-0$ & $5-0$ & $4.75-300$ & $4.75-600$ \\
\hline Dead (Number) & ${ }^{b} 0 \pm 0$ & ${ }^{\mathrm{a}} 8.5 \pm 17.66$ & $a_{5.5} \pm 18.66$ & ${ }^{a} 1.5 \pm 21.66$ & $b_{1} \pm 3$ & ${ }^{a} 1.5 \pm 24.66$ & ${ }^{\mathrm{a}} 2.5 \pm 20.66$ \\
\hline Swimmer (Number) & ${ }^{\mathrm{a}} 0 \pm 30$ & ${ }^{b} 0 \pm 0$ & ${ }^{b} 0 \pm 0$ & ${ }^{b} 0 \pm 0$ & ${ }^{b} 0 \pm 0$ & ${ }^{b} 0 \pm 0$ & ${ }^{b} 0 \pm 0$ \\
\hline Non-Swimming (Number) & ${ }^{c} 0 \pm 0$ & $8.5^{b} \pm 12.33$ & $5.5^{b} \pm 11.33$ & $1.5^{b} \pm 8.33$ & $1^{\mathrm{a}} \pm 27$ & $1.5^{b} \pm 5.33$ & $2.51^{b} \pm 9.33$ \\
\hline Yolk-sac length (mm) & ${ }^{d} 0.02 \pm 0.1$ & ${ }^{b} 0.3 \pm 1.19$ & ${ }^{\mathrm{b}} 0.35 \pm 1.10$ & ${ }^{c} 0.04 \pm 0.62$ & ${ }^{c} 0.03 \pm 0.48$ & ${ }^{b} 0.19 \pm 1.17$ & ${ }^{\mathrm{a}} 0.23 \pm 1.93$ \\
\hline
\end{tabular}

Different letters denote a significant difference at the same row $(P<0.05)$.

days and in the all experiment treatments lost their swimming ability. There was significant difference in the number of dead larvae and the number of nonswimming larvae between control group and larvae exposed to acidic waters and waters containing $300 \mathrm{mg} \mathrm{L}^{-1}$ of aluminum and pH $4.75(\mathrm{p}<0.05)$ and lowest number of non-swimming larvae was observed in the control group. Also the highest of yolk-sac length belong to the waters containing $600 \mathrm{mg} \mathrm{L}^{-1}$ of aluminum and $\mathrm{pH} 4.75$ and then highest of yolk-sac length belong to waters with $\mathrm{pH} 4.25$ and $\mathrm{pH} 4.5$ and also waters containing $300 \mathrm{mg} \mathrm{L}^{-1}$ of aluminum and $\mathrm{pH} 4.75$. There was significant difference among control group and acidic waters and waters containing aluminum (Table 2).

larval were exposed in acidic waters with $\mathrm{pH} 6.5$ and waters containing 50 and $100 \mathrm{mgL}^{-1}$ of aluminum for the 10 days that results of means comparison this experimental doses are given in Table 3.

As shown in Table 3, There was no significant difference between groups that exposed to waters containing 50 and $100 \mathrm{mgL}^{-1}$ of aluminum and there was significant difference in number of dead larvae and number of swimmer larvae and also non swimmer larvae between control group and larvae exposed to waters containing 50 and $100 \mathrm{mgL}^{-1}$ of aluminum and $\mathrm{pH}$ 6.5. The highest number of gill cover movements was observed in control group $(\mathrm{P}<0.05)$. The lowest number of heartbeat significantly belong to larvae that were exposed $50 \mathrm{mgL}^{-1}$ of aluminum and $\mathrm{pH} 6.5$ than other experiment doses $(\mathrm{P}<0.05)$ (Table 3$)$.

\section{Discussion}

\section{Mortality}

Exposure of Goldfish to lower $\mathrm{pH}$ levels $<5.75$ reduced survival compared to $\mathrm{pH}$ levels of 6-7. In this study, high mortality occurred around $\mathrm{pH} 4-5.75$. The highest mortality was observed in $\mathrm{pH} 5.75$ after 3 days; this could be because of the disturbance of ion balance. Similarly, Howells et al. (1990) and Keinanen et al. (2000) concluded that the cause of death in aluminum exposed fish was predominantly the disturbance of ion balance. Because, acidic water and $\mathrm{Al}$ interferes with ion balance of fish by increasing ion efflux and by inhibiting the uptake of essential ion from the environment.

Several authors have demonstrated the influence of $\mathrm{pH}$ 4.5- 5.6 on aquaculture fish in a wide range of hardness variation. Jezierska and Witeska (1995) observed total mortality in common carp larvae at pH 5.5. In generally, most teleost exposed to acidic or alkaline waters showed a higher survival than in soft waters (Parra and Baldisserotto 2007).

After 7 days, the highest mortality was observed in $\mathrm{pH}$ 4-4.75 And $\mathrm{Al} 300$ and $600 \mathrm{mgl}^{-1}$. Some researchers showed that high concentration of $\mathrm{Al}$ in combination with low $\mathrm{pH}$ have been shown to cause mortality of freshwater fish in both field and laboratory studies (Atland and Barlaup, 1995). Al toxicity depends on the species of $\mathrm{Al}$ present, which is largely dependent on $\mathrm{pH}$ (Burrows 1997). Therefore, in the present study, it was found that a combination of low $\mathrm{pH}$ and $\mathrm{Al}$ is toxic to larval.

Table 3 The means comparison of evaluated parameters of yolk-sac fry of Goldfish after exposure to 50 and $100 \mathrm{mgL}^{-1}$ of aluminum and acidic waters with $\mathrm{pH} 6.5$ for 10 days

\begin{tabular}{|c|c|c|c|c|}
\hline Parameters & Control & $6.5-0$ & $6.5-50$ & $6.5-100$ \\
\hline Dead & $0 \pm 0^{c}$ & ${ }^{a} 1.52 \pm 18.33$ & $b_{5.03 \pm 10.66}$ & $\mathrm{~b}_{1.73 \pm 11}$ \\
\hline Swimming & $0 \pm 30^{\mathrm{a}}$ & ${ }^{c} 0 \pm 0$ & $b_{8.08} \pm 15.33$ & ${ }^{c} 0 \pm 0$ \\
\hline Non-swimmer & ${ }^{c} 0 \pm 0$ & $b_{1.52 \pm 11.66}$ & ${ }^{b} 6 \pm 6$ & ${ }^{a} 1.73 \pm 19$ \\
\hline Total length (mm) & ${ }^{\mathrm{a}} 0.57 \pm 79.66$ & $b_{2.51 \pm 67.66}$ & ${ }^{\mathrm{a}} 0.57 \pm 77.33$ & ${ }^{\mathrm{a}} 1.15 \pm 78.33$ \\
\hline Gill cover movements & ${ }^{a} 1.52 \pm 20.33$ & $b_{1.52 \pm 12.33}$ & $b_{1.52 \pm 11.66}$ & $\mathrm{~b}_{1} \pm 10$ \\
\hline Heartbeat & $\mathrm{a}_{2} \pm 42$ & $\mathrm{a} 1 \pm 40$ & $b_{1} .52 \pm 35.33$ & $\mathrm{a} 1.73 \pm 41$ \\
\hline
\end{tabular}

Different letters denote a significant difference at the same row $(P<0.05)$. 
It has been suggested that the embryonic and larval fish stages are most sensitive to $\mathrm{pH}$ changes (Heydarnejad, 2012). Heydarnejad (2012) stated that larval of common carp grew and survived best when exposed to a water $\mathrm{pH}$ of 7.5-8.

\section{Larval development}

In the present study exposed larval have more yolk-sac remaining as compared with control group. Indeed, absorption of yolk-sac fry in acidic water was delayed. Consequently, decreasing of absorption of yolk-sac leading to reduced growth. Similarly, Catla (2002) stated that a sub-lethal exposure at an early age retards larval development and thus exposed animals have more yolk-sac remaining as compared with control animals.

Increasing of the retarded absorption of yolk and, as a consequence, retarded growth of yolk-sac fry by $\mathrm{Al}$ in acidic water was equally evident in some species including pike (Keinanen et al. 2000).

Decreasing of swimming in newly-hatched Goldfish in all of the concentration of $\mathrm{Al}$ after 7 and 10 days, indicate that Goldfish larval is sensitive to low $\mathrm{pH}$ and acidic waters. Similarly results were obtained by Vuorinen et al. (1993) and Keinanen et al. (2000). Al in acidic water clearly augments both the decrease of activity and retardation of yolk absorption and consequently the development and growth of yolk-sac fry (Vuorinen et al. 1993).

The present study shows that the potential for routine swimming behavior to recover during continued exposure is dose-dependent. It was the respiratory stress caused by exposure to $\mathrm{Al}$ which resulted in the shutdown of routine swimming behavior (Alin and Wilson 2000). In yolk- sac fry, the routine metabolic rate may, in contrast, be reduced as acidity decreases their swimming activity as documented mainly in salmonoid fishes (Sayer et al. 1993a. Sayer et al. 1993b).

Allin and Wilson (1999) recently provided evidence for a loading influence of $\mathrm{Al}$ and low $\mathrm{pH}$ on metabolism by showing that juvenile rainbow trout reduce their swimming activity in order to maintain their routine metabolic rate at control levels when exposed to acidic water and Al.

In the present study, the movement of operculum decreased in acidic water at high $\mathrm{Al}$ concentration. Also, heart rate was lower in low $\mathrm{pH}$ and $\mathrm{Al}$. similarly, Keinanen et al. (2000) stated that the ventilation rate and specific $\mathrm{O}_{2}$ consumption rate of Pike decreased most in acidic water at high $\mathrm{Al}$ concentrations. Also, Keinanen et al. (2000) observed that heart rate of Pike yolk-sac fry tendency toward a lower in more acidic and $\mathrm{Al}$ containing water.

\section{Conclusion}

Goldfish larval can be tolerate wide range of water $\mathrm{pH}$ Higher survival was verified at $\mathrm{pH}$ between 5.75 and 6.7 .
Generally, low $\mathrm{pH}$ in combination with high $\mathrm{Al}$ is more toxic to larval Goldfish. This results showed that Goldfish larval is sensitive to low $\mathrm{pH}$ and acidic waters, and in acidic water swimming activity and absorption of yolk-sac is decreased.

\section{Competing interests}

Vahid Taghizadeh: Fish reproduction \& culture researcher. Mohammadreza Imanpoor: Fish reproduction \& culture researcher. Mahboubeh Hosseinzadeh: Fish reproduction \& culture researcher. Hajar Azarin: Fish reproduction \& culture researcher.

\section{Authors' contributions}

$V T, M M I, M H$ and $\mathrm{HA}$ approved the manuscript. All authors read and approved the final manuscript.

\section{Acknowledgments}

The authors thank the aquaculture research center and Fisheries group of the Gorgan University of Agricultural Sciences and Natural resources; for the supply of research material.

Received: 11 April 2013 Accepted: 24 April 2013

Published: 27 April 2013

\section{References}

Alin CJ, Wilson RW (2000) Effects of pre-acclimation to aluminum on the physiology and swimming behavior of juvenile rainbow trout (Oncorhynchus mykiss) during a pulsed exposure. Aquat Toxicol 51:213-224

Allin CJ, Wilson RW (1999) Behavioral and metabolic effects of chronic exposure to sub lethal aluminum in acidic soft water in juvenile rainbow trout (oncorhynchus mykiss). Can J Fish Aquat Sci 56:670-678

Atland A, Barlaup BT (1995) Avoidance of toxic mixing zones by Atlantic salmon (Salmo salar) in the limed river Audna, Southern Norway. Environ Pollut 90:203-208

Burrows WD (1997) Aquatic aluminum: chemistry, toxicity and environmental prevalence. CRC Crit Rev Environ Control 7:167-216

Catla M (2002) Does brown trout (salmo trutta L.) larval development retardation caused by short-term exposure to low $\mathrm{pH}$ and elevated aluminum concentration affect a second episode of toxicity? Apply Ichthyology 18:210-215

Heydarnejad MS (2012) Survival and growth of common carp (Cyprinus carpio) exposed to different water pH levels. Turkish J Veterinary Animal Sci 36:245-249

Howells G, Dalziel TRK, Reader J, Solbe JF (1990) EIFAC water quality criteria for European fresh water fish: report on aluminum. Chem Ecol 4:117-173

Jezierska B, Witeska M (1995) The influence of pH on embryonic development of common carp (Cyprinus carpio). Arch Pol Fish 3:85-94

Kane DA, Rabeni CF (1987) Effects of aluminum and pH on the early life stages of smallmouth bass (Micropterus dolomieu). Water Res 21:633-639

Keinanen M, Peuranen S, Nikinmaa M, Tigerstedt C, Vuorinen P (2000) Comparison of the responses of the yolk-sac fry of Pike (Esox lucius) and Roach (Rutilus rutilus) to low pH and aluminum: sodium influx, development and activity. Aquat Toxicol 47:161-179

Leino RL, McCormick JH, Jensen KM (1990) Multiple effects of acid and aluminum on brood stock and progeny of fathead minnows, with emphasis on histopathology. Can J Zool 68:234-244

Mani Sharma C (2003) Effects of exposure to aluminum on fish in acidic waters. The Department of Ecology and Natural Resource Management (INA) Agricultural University of Norway. J World Ecol 56:17-22

McCormick JH, Jensen KM, Anderson LE (1989) Chronic effects of low pH and elevated aluminum on survival, maturation, spawning and embryo-larval development of the fathead minnow in soft water. Water Air Soil Pollute 43:293-307

Parra JEG, Baldisserotto B (2007) Effect of water pH and hardness on survival and growth of freshwater teleosts. In: Baldisserotto B, Mancera JM, Kapoor BG (eds) Fish osmoregulation. Science Publishers, Enfield, pp 43-48

Peterson RH, Daye PG, Lacroix GL, Garside ET (1982) Reproduction in fish experiencing acid and metal stress. In: Johnson RE (ed) Fisheries proceedings of an international symposium on acidic precipitation and fishery impacts in northeastern north America. Cornell University, Ithaca, New York, pp 177-196 
Rask M, Tuunainen P (1990) Acid-induced changes in fish populations of small Finnish lakes. In: Kauppi P, Anttila P, Kenttämies K (eds) Acidification in Finland. Springer, Berlin, pp 911-927

Sayer MDJ, Reader JP, Dalziel TRK (1993a) Freshwater acidification: effects on the early life stages of fish. Rev. Fish Biology Fish 3:95-132

Sayer MDJ, Reader JP, Morris R (1993b) Embryonic and larval development of Brown trout (Salmo trutta) exposure to aluminum, copper, lead in soft acidic water. J Fish Biol 38:431-455

Smith R, Haines T (1995) Mortality, growth, swimming activity and gill morphology of Brook trout (Salvelinus fontinalis) and Atlantic salmon (Salmo salar) exposed to low pH with and without aluminum. Environ Pollut 1:33-40

Vuorinen M, Vuorinen PJ, Hoikka J, Peuranen S (1993) Lethal and sublethal threshold values of aluminum and acidity to Pike (Esox lucius), Whitefish (Coregonus lavaretus), Pike perch (Stizostedion lucioperca) and Roach (Rutilus rutilus) yolk-sac fry. Sci Total Environ Supply Supply17:953-967

Wilson RW, Bergman HL, Wood CM (1994) Metabolic costs and physiological consequences of acclimation to aluminum in juvenile Rainbow trout (Oncorhynchus mykiss). 2: gill morphology, swimming performance, and aerobic scope. Can J Fish Aquat Sci 51:536-544

doi:10.1186/2193-1801-2-190

Cite this article as: Taghizadeh et al:: Effects of acidic water in combination with aluminum on swimming behavior and survival of yolk-sac larval in Goldfish (Carassius auratus gibelio). SpringerPlus 2013 2:190

\section{Submit your manuscript to a SpringerOpen ${ }^{\circ}$ journal and benefit from:}

- Convenient online submission

- Rigorous peer review

- Immediate publication on acceptance

Open access: articles freely available online

- High visibility within the field

- Retaining the copyright to your article 